\title{
Expression and Localization of Urinary Trypsin Inhibitor in the Rat Embryo
}

\author{
Tomohiko Wakayama and Shoichi Iseki \\ Department of Anatomy, School of Medicine, Kanazawa University, Kanazawa 920-0934
}

Received for publication November 6, 1997 and in revised form January 13, 1998

\begin{abstract}
Urinary trypsin inhibitor (UTI) is an acidic protein with anti-proteolytic activity that constitutes the active domain of serum inter$\alpha$-trypsin inhibitor. UTI has been demonstrated not only in the adult urine but also in the amniotic fluid of late pregnancy. In order to examine the expression and localization of UTI in the rat embryo and placenta, we performed a combination of reverse transcription-polymerase chain reaction (RTPCR), in situ hybridization and immunohistochemistry. UTI mRNA expression was detected by RT-PCR in the embryo on and after the day 12 of gestation (E12) but not in the placenta throughout the prenatal period. In situ hybridization revealed that UTI transcripts were localized in the liver but not in any other organs of embryo from E12 through E20. On the other hand, UTI im-

liver from $\mathrm{E} 12$ but also in the kidney and intestine from E18. On electron microscopy, the immunoreactivity of liver was localized to the surface of hepatocytes and the lysozomes of Kupffer cells, whereas the endothelial cells and hematopoietic cells were free of the reaction. In contrast, the immunonoreactivities of kidney and intestine were localized exclusively to the apical lysosomes of proximal tubular epithelial cells and absorptive epithelial cells, respectively. These results indicated that in the rat embryo, as in the adult, the hepatocyte is the only site for production of UTI, that UTI is excreted into the urine and thereby into the amniotic fluid, and that a part of amniotic UTI is reabsorbed in the fetal intestine, suggesting a possible role of UTI in the protection of the fetus during the late pregnancy.
\end{abstract} munoreactivity was detected not only in the

Key words: Urinary trypsin inhibitor (UTI), RT-PCR, In situ hybridization, Immunohistochemistry, Development, Rat (Wistar)

\section{Introduction}

Urinary trypsin inhibitor (UTI), also referred to as urinastatin, HI-30, ASPI or bikunin, is an acidic glycoprotein with 143 amino acid residues present in the urine of both human and rodents $[4,8,12,30,34]$. In the serum, UTI represents the functional domain of inter- $\alpha$-trypsin inhibitor (ITI). ITI is composed of 2 heavy chains and a light chain identical with UTI, which are coded by 3 different genes $[1,9,10,18,23,26]$. UTI has two Kunitztype peptide domains that inhibit the activity of a variety of proteinases, including trypsin, chymotrypsin, plasmin, cathepsin $G$ and neutrophil elastase $[18,21]$. Although the physiological significance of UTI is still unclear, it has been used for many clinical purposes including the treatment of acute pancreatitis based on its anti-proteolytic

Correspondence to: Dr. Tomohiko Wakayama, Department of Anatomy, School of Medicine, Kanazawa University, 13-1 Takaramachi, Kanazawa 920-0934, Japan. activity [20].

In regard to the expression and cellular localization of UTI, our previous study in the adult rat has revealed that, while the hepatocyte is the only site for expression of UTI mRNA, the immunoreactivity for UTI is present not only in the hepatocytes but also in the Kupffer cells of the liver and the proximal tubular epithelial cells of kidney, suggesting that UTI produced by the hepatocytes is partly reabsorbed in the liver and kidney and thereby regulates its concentrations in the blood and urine [35].

It remains to be examined, however, if the expression and cellular localization of UTI obtained in the adult is also applicable to the embryo. There is evidence that systems of proteases and their inhibitors play important roles in the embryonic organ differentiation $[24,27,31]$. Furthermore, UTI is present in the amniotic fluid of late pregnancy, suggesting its role in the maintenance of pregnancy [16]. In the present study, to elucidate the expression and localization of UTI in the embryo as well as the origin and fate of amniotic UTI, we have examined the 
embryo and placenta of the rat with a combination of histochemical methods that detect the mRNA and immunoreactivity of UTI.

\section{Materials and Methods}

\section{Animals and tissue preparation}

Adult female Wistar strain rats with normal estrous cycles were purchased from Japan SLC, Inc. (Hamamatsu, Japan) and mated with males under standard laboratory conditions. Vaginal smears were examined every morning and the day of sperm positivity was designated as embryonic day 0 (E0). Fetuses and placentas at different stages, i.e., E10, E12, E14, E16, E18 and E20, were removed from the uteri after anesthetizing the pregnant rats with intraperitoneal injection of sodium pentobarbital $(50 \mathrm{mg} / \mathrm{kg}$ body weight). For reverse transcription-polymerase chain reaction (RT-PCR), the embryos and placentas were frozen separately in liquid nitrogen and stored at $-80^{\circ} \mathrm{C}$ until use for RNA extraction. Only in the case of E10, the whole conceptive including both embryo and placenta was used as specimen. For in situ hybridization and immunohistochemistry, the embryos and placentas were fixed by immersion in $4 \%$ paraformaldehyde in $0.1 \mathrm{M}$ phosphate buffer ( $\mathrm{pH}$ 7.2) for $4 \mathrm{hr}$ at $4^{\circ} \mathrm{C}$ and then rinsed in phosphate buffer containing $30 \%$ sucrose overnight at $4^{\circ} \mathrm{C}$ for cryoprotection.

\section{Oligonucleotide primers and probes}

The sequences of the synthetic oligonucleotides used for RT-PCR, Southern blotting and in situ hybridization analyses were as follows. UTI 5'primer, 5'TGCAGAGCCATGCAGGGTCTC3'(nucleotides 12-32); UTI 3'primer, 5'GCTACCCTCTGGCTTGCAGAC3'(complement of 1079-1099); UTI probe, 5'TATGGTCCGGCACGTCTGCAGGCATTCCTT3'(complement of 840-869); and sense-UTI probe, 5'AAGGAATGCCTGCAG-ACG TGCCGGACCATA3'(840-869) were synthesized according to published rat UTI cDNA sequence [14] and kindly given to us by Bioscience Research Laboratory, Mochida Pharmaceutical Co., Ltd., Tokyo, Japan. Glyceraldehyde3-phosphate dehydrogenase (G3PDH) 5'primer, 5'ACCACAGTCCATGCCATCAC3' (nucleotides586-605) and G3PDH 3'primer, 5'TCCACCACCCTGTTGCTGTA3' (complement of 1018-1037) were purchased from Clontech Laboratories, Palo Alto, Ca.

\section{$R T-P C R$}

Total RNA was extracted from each frozen specimen by the acid guanidinium thiocyanate-phenol-chloroform method [6], using a kit (RNAzol) from Tel-Test, Inc., Friendswood, Tex. Aliquots of each total RNA sample, $0.5 \mu \mathrm{g}-20 \mu \mathrm{g}$ in amount, were subjected to reverse transcription (RT) at $42^{\circ} \mathrm{C}$ for $90 \mathrm{~min}$ using Moloney murine leukemia virus reverse transcriptase (Toyobo Inc., Osaka, Japan). Subsequently, an aliquot of each RT product was amplified in a DNA thermal cycler (MJ Research,
Inc., Watertown, Mass.), using Taq DNA polymerase (Takara Shuzo, Kyoto, Japan) and a pair of 21-base primers spanning $1087 \mathrm{bp}$ length of the coding region of rat UTI cDNA in a mixture of $100 \mu \mathrm{l}$. Each amplification cycle consisted of $94^{\circ} \mathrm{C}$ for $30 \mathrm{sec}, 60^{\circ} \mathrm{C}$ for $1 \mathrm{~min}$ and $72^{\circ} \mathrm{C}$ for $2 \mathrm{~min}$. For positive control, the reaction using G3PDH primers was also performed. After 10-30 cyles of amplification, a $20 \mu \mathrm{l}$ aliquot of each RT-PCR mixture was electrophoresed on a $1 \%$ agarose gel, blotted onto nylon membrane (Pall BioSupport, East Hills, NY) according to Southern blot procedure [29]. A 30-base antisense oligonucleotide probe for rat UTI mRNA was labeled at the $3^{\prime}$ end with $\left[\alpha{ }^{-32} \mathrm{P}\right] \mathrm{dCTP}$ (Du Pont, Wilmington, DE) using terminal deoxyribonucleotidyl transferase (BRL, Gaithersburg, MD) and was hybridized with the membrane. After washing, the relative radioactivities of the hybridization bands were measured with a BAS2000 BioImage analyzer (Fuji Photo Film Co. Ltd., Hamamatsu, Japan) and subsequently the membrane was exposed to Kodak X-Omat AR film for autoradiography.

\section{In situ hybridization}

The fixed and cryoprotected embryos were cut into $14 \mu \mathrm{m}$ sections on a cryostat and mounted on gelatincoated glass slides. After being air-dried, they were fixed with $4 \%$ paraformaldehyde/0.1 M phosphate buffer ( $\mathrm{pH} 7.2$ ) for $15 \mathrm{~min}$, washed with PBS containing $2 \mathrm{mg} / \mathrm{ml}$ glycine, acetylated with $0.25 \%$ acetic anhydride $/ 0.1 \mathrm{M}$ triethanolamine $(\mathrm{pH} \mathrm{8.0)}$, and pre-hybridized at room temperature for $2 \mathrm{hr}$. The pre-hybridization solution was composed of $50 \%$ deionized formamide, $4 \times \mathrm{SSC}, 0.1 \mathrm{M}$ phosphate buffer (pH 7.2), $1 \times$ Denhardt's solution, $2 \%$ sodium N-lauroyl sarcosinate, $20 \mathrm{mM}$ 2-mercaptoethanol, and $250 \mathrm{mg} / \mathrm{ml}$ denatured salmon sperm DNA. After rinse in $2 \times$ SSC and dehydration with a graded ethanol series, the sections were hybridized with the ${ }^{35} \mathrm{~S}$-labeled probes added at $1.0 \times 10^{6} \mathrm{dpm}$ to $100 \mu \mathrm{l}$ of pre-hybridization solution for each slide. Two kinds of negative control experiments were performed. One was to replace the labeled antisense probe with the labeled sense probe, and the other to add an excess amount of unlabeled antisense probe $(200$ times that of labeled probe) to the probe mixture. After incubation for $16 \mathrm{hr}$ at $37^{\circ} \mathrm{C}$, the slides were washed with three changes of $0.3 \times \mathrm{SSC}$ with $0.1 \%$ sodium N-lauroyl sarcosinate for a total of $3 \mathrm{hr}$ at $37^{\circ} \mathrm{C}$ and dehydrated with a graded ethanol series containing $0.3 \mathrm{M}$ ammonium acetate. The air-dried slides were first exposed to BIOMAX (Kodak) for 10 days for macroautoradiography, and then were dipped in Kodak NTB-2 emulsion and exposed for up to 3 weeks at $4^{\circ} \mathrm{C}$ for microautoradiography. They were then developed in Kodak D19, stained with hematoxylin and eosin, and examined with an Olympus BH-2 microscope under bright- and dark field conditions.

\section{Immunohistochemistry}

A polyclonal antiserum against purified human UTI $\left(\right.$ Miraclid $^{R}$ ) was raised in a rabbit, and its IgG fraction was 
purified and kindly provided to us by Mochida Pharmaceutical Co., Ltd., Tokyo, Japan. On a Western blot analysis, this antibody was confirmed to react specifically with human UTI and also form a single immunoreactive band with the urine, liver homogenate and kidney homogenate from adult rats [35]. For light microscopic immunohistochemistry, the cryostat sections were treated successively with $0.3 \%$ Triton-X100 in PBS for $1 \mathrm{hr}$ for cell permeabilization, $0.3 \% \mathrm{H}_{2} \mathrm{O}_{2}$ in methanol for $10 \mathrm{~min}$ for inhibition of intrinsic peroxidase activity and $5 \%$ normal porcine serum for $30 \mathrm{~min}$ for prevention of non- specific antibody binding. Subsequently, the sections were incubated overnight at room temperature with anti-UTI antibody at the concentration of $0.54 \mu \mathrm{g} / \mathrm{ml}$. For negative control, the antibody was absorbed by purified human UTI $(100 \mu \mathrm{g} / \mathrm{ml}$, a kind gift of Mochida Pharmaceutical Co., Ltd.) for $4 \mathrm{hr}$ at $4^{\circ} \mathrm{C}$ prior to use. After the sections were washed in PBS, the sites of immunoreaction were visualized by incubating the sections successively with biotinylated anti-rabbit IgG antibody for $1 \mathrm{hr}$, horseradish peroxidase-conjugated streptavidin for $1 \mathrm{hr}$ and $3,3^{\prime}$ diaminobenzidine solution containing $\mathrm{H}_{2} \mathrm{O}_{2}$ for a few
A

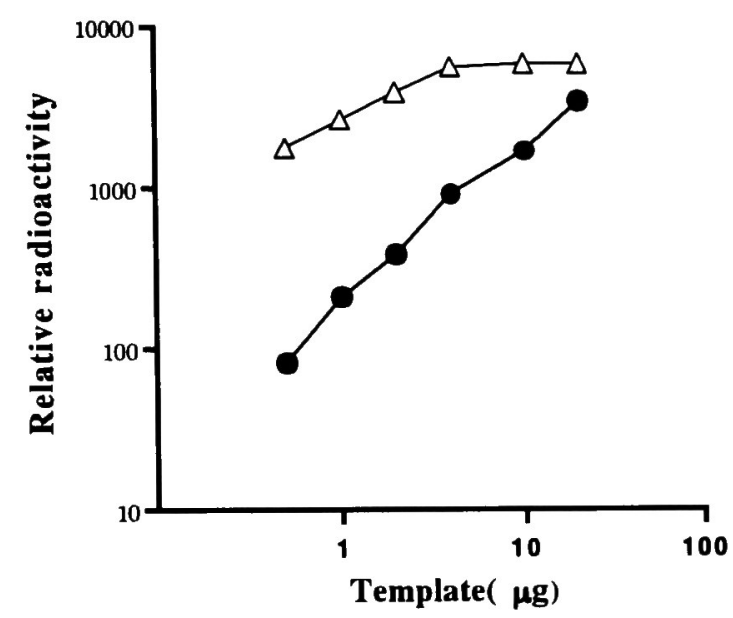

B

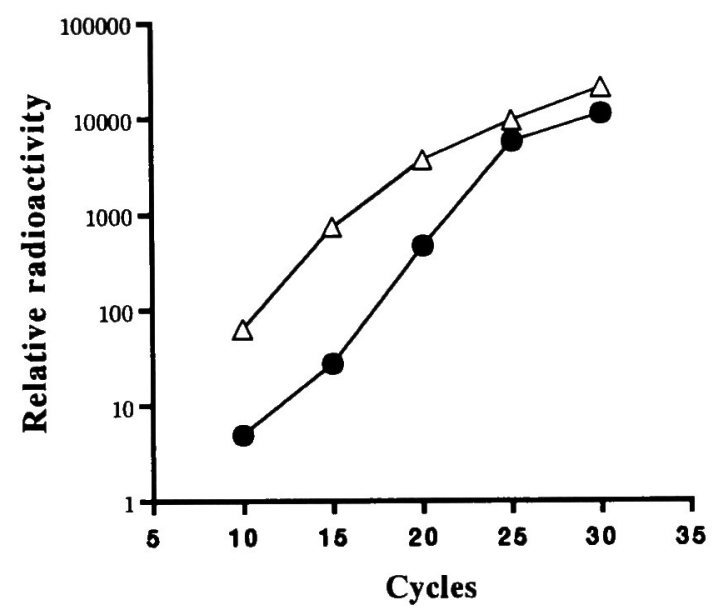

Fig. 1. Quantitative RT-PCR analysis of UTI mRNA. The total RNA from E12 embryo was used as template and subjected to RT-PCR using UTI and G3PDH primers. The amplified products were electrophoresed, blotted and hybridized with ${ }^{32}$ P-labeled UTI and G3PDH probes. The signal intensities of hybridization bands were measured with image analyzer and expressed as the arbitrary logarithm values of radioactivities. The values for UTI product $(O)$ and G3PDH product $(\triangle)$ were plotted against template amounts $(\mathbf{A}$; the cycle number is 20$)$ and against cycle numbers (B; the template amount is $2 \mu \mathrm{g}$ ).

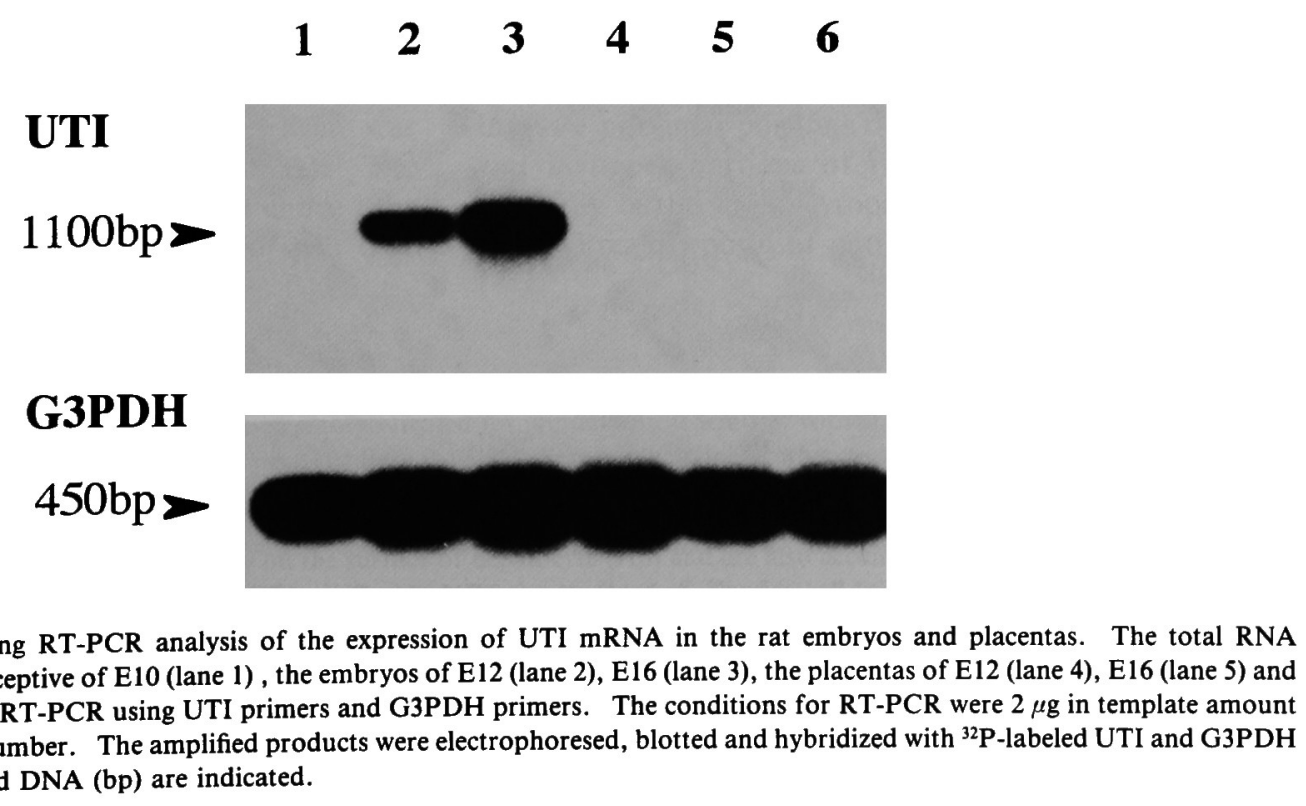

Fig. 2. Autoradiograms showing RT-PCR analysis of the expression of UTI mRNA in the rat embryos and placentas. The total RNA specimens from the whole conceptive of E10 (lane 1), the embryos of E12 (lane 2), E16 (lane 3), the placentas of E12 (lane 4), E16 (lane 5) and E20 (lane 6) were subjected to RT-PCR using UTI primers and G3PDH primers. The conditions for RT-PCR were $2 \mu \mathrm{g}$ in template amount and 20 in amplification cycle number. The amplified products were electrophoresed, blotted and hybridized with ${ }^{32}$ P-labeled UTI and G3PDH probes. The sizes of amplified DNA (bp) are indicated. 
minutes, using a LSAB2 kit (Dakopatts, Glostrup, Denmark).

For electron-microscopic immunocytochemistry, the immuno-gold method was performed. The specimens fixed with $4 \%$ paraformaldehyde were dehydrated in graded ethanol series, embedded in LR-White Resin (London Resin, London, U.K.) containing $1 \%$ benzoil peroxide, and polymerized for $48 \mathrm{hr}$ at room temperature with an ultraviolet polymerizer. Ultrathin sections were cut with a microtome, mounted on nickel grids and incubated overnight at $4{ }^{\circ} \mathrm{C}$ with anti-UTI antibody at the concentration of $0.54 \mu \mathrm{g} / \mathrm{ml}$. The sites of immunoreaction were then visualized by incubating the sections with colloidal $20 \mathrm{~nm}$ gold-conjugated anti-rabbit IgG antibody (British BioCell,
Cardiff, U.K.). After being washed in PBS and then in distilled water, the sections were briefly stained with $2 \%$ uranyl acetate and subjected to observation with a Hitachi $\mathrm{H}-700$ electron microscope.

\section{Results}

\section{Expression of UTI $\mathrm{mRNA}$ in the embryo}

Fig. 1 shows the titration of cDNA products in RT-PCR of total RNA from E12 embryo with UTI and G3PDH primers by hybridization with ${ }^{32} \mathrm{P}$-labeled probes. The intensities of both signals elevated linearly as the amount of template RNA increased up to $4 \mu \mathrm{g}$ and the number of amplification up to 25 cycles. Accordingly,

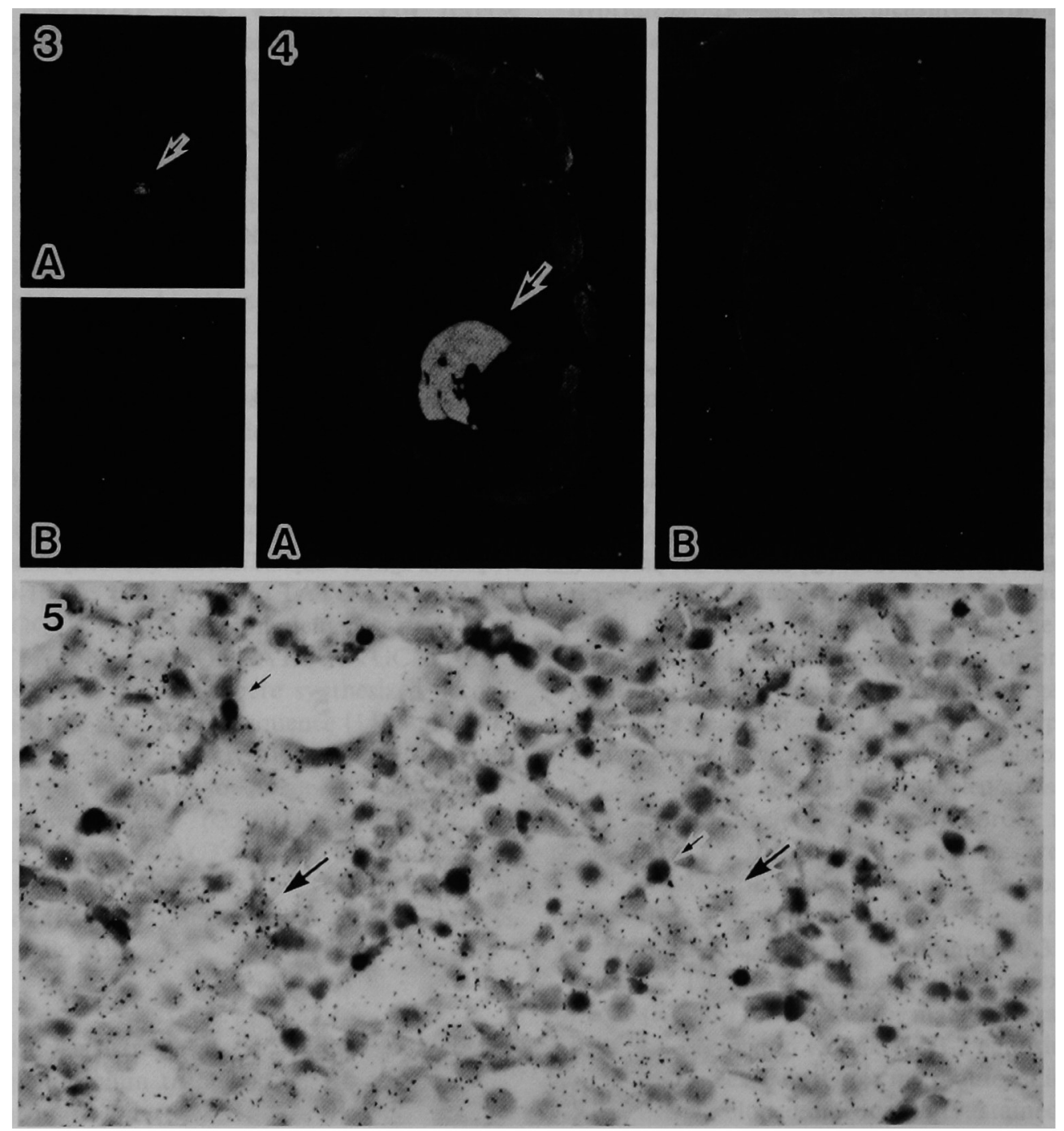

Figs. 3, 4. Macro-autoradiograms showing in situ hybridization of E12 $(3 \mathrm{~A}, \mathbf{B})$ and E16 $(4 \mathrm{~A}, \mathbf{B})$ embryos with ${ }^{35} \mathrm{~S}$-labeled UTI probe in the absense (3A, 4A) and presence (3B, 4B) of excess amount of unlabeled UTI probe. 3A, 4A: The signal representing UTI mRNA is exclusively localized to the liver (arrows). 3B, 4B: No signal is recognized in any organs. $\times 5$.

Fig. 5. Micro-autoradiogram showing in situ hybridization of the liver from E16 embryo with UTI probe. The silver grains representing UTI mRNA signal is located mostly in the hepatocytes with large pale nuclei (large arrows), whereas they are scarcely recognized in the mesenchymal cells with small or round dark nuclei (small arrows). $\times 300$. 
RT-PCR was performed with $2 \mu \mathrm{g}$ of templates for 20 cycles for all samples (Fig. 2). No signal for amplified UTI cDNA was detected in the whole conceptive of E10. The signal at the size of $1100 \mathrm{bp}$ first appeared in E12 embryo, increased in intensity until E18, where it reached a plateau and was maintained until E20. In contrast, no UTI cDNA signal was detected in the placentas throughout the observation period. Under the same conditions, the signal for G3PDH cDNA was detected with similar intensities in all embryos and placentas from E10 through E20, confirming the intact template activities of all RNA samples examined. These results indicated that a detectable amount of UTI mRNA occurs in the rat embryo as early as at E12, whereas no UTI mRNA occurs in the placenta throughout the pregnancy.

\section{Localization of UTI mRNA in the fetal liver}

On macroautoradiography, no hybridization signal for UTI mRNA was deteced in any portions of E10 embryo, in an agreement with the result of RT-PCR. At $E 12$, an intense signal was recognized in the liver but not in any other portions of embryo (Fig. 3A, B). The signal continued to be localized to the liver with increasing intensity until E20 (Fig. 4A, B). In contrast, no signal was detectable in the placenta throughout the examined period. On microautoradiography, the silver grains representing UTI mRNA signal were distributed over the entire liver lobule from E12 through E20. At the cellular level, the grains appeared to be localized primarily in the hepatocytes and not in the mesenchymal cell populations including the hematopoietic cells (Fig. 5). These results indicated that, beginning from E12, the liver and the hepatocyte are the only organs and the entire population, respectively, in rat embryo that express a detectable amount of UTI mRNA.

Immunohistochemical localization of UTI in the fetal liver

On light microscopic immunohistochemistry, no staining with anti-UTI antibody was recognized in E10 embryo or in the placenta throughout the examined period. In the embryos from E12 through E20, the liver was immunostained with moderate intensity (Fig. 6A). The immunoreactivity distributed diffusely on the entire liver lobule. When the antibody was preabsorbed with UTI oligopeptide, the liver staining was abolished completely, confirming the specificity of the immunoreaction (Fig. 6B). On electron microscopic immunocytochemistry, gold particles representing UTI-immunoreactivity were distributed primarily on the surface of hepatocytes facing the sinusoidal capillary (Fig. 7), whereas they were scarcely found in the cytoplasm of hepatocytes. The immunoreactivity was also present with high intensity in the lysosomes of Kupffer cells. No apparent reactivity was recognized on the surface of Kupffer cells or in any portions of sinusoidal endothelial cells and hematopoietic cells.

\section{Immunohistochemical localization of UTI in the fetal kidney}

Before E18, no UTI immunoreactivity was recognized in the organs other than the liver. In the embryos from E18 through E20, however, portions of the kidney were stained intensely with anti-UTI antibody (Figs. 8, 9). The immunoreactivity was localized primarily in the proximal convoluted tubuli of renal cortex, where the apical cytoplasm of epithelial cells showed a granular appearance with immunostaining. The other portions of cortex as well as the medulla showed no apparent immunostaining. Preabsorption of anti-UTI antibody with purified UTI abolished the reaction, confirming the specificity of immunoreaction (not shown). On electron microscopic immunocytochemistry of proximal tubular epithelial cells (Fig. 10), abundant gold particles were accumulated exclusively in the large vacuoles occupying the apical cytoplasm, which were identified as lysosomes according to previous literatures [25]. The immunoreactivity was also found in the basal lamina of glomerulus., whereas other portions of kidney, including the distal tubulus and collecting duct, were free of the reaction.

\section{Immunohistochemical localization of UTI in the fetal intestine}

In the embryos from E18 through E20, portions of the intestine were stained moderately with anti-UTI antibody (Figs. 11, 12). The immunoreactivity was stronger in more proximal portions of the duodenum-rectum axis and in upper portions of the crypt-villus axis, located primarily in the apical cytoplasm of absorptive epithelial cells. Preabsorption of anti-UTI antibody with purified

Fig. 6. Light micrographs of the abdominal part of E16 embryo treated for immunohistochemistry with anti-UTI antibody (A) and anti-UTI antibody preabsorbed with purified human UTI (B). A: The liver (L) is diffusely immunostaied, whereas the kidney (K) and intestine (I) are immunonegative. B: No immunostaining is recognized in any organs. $\times 40$.

Fig. 7. Electron micrographs of the liver from E16 embryo treated for immunocytochemistry with anti-UTI antibody. Gold particles representing UTI immunoreactivity are deposited abundantly on the surface of hepatocyte (Hp) and are also accumulated in the lysosome (arrow) of Kupffer cell $(\mathbf{K})$. No appreciable numbers of particles are present on the surfaces of Kupffer cell, sinusoidal endothelial cell (E) and hematopoietic cell $(\mathrm{Hm}) . \times 21,000 ; \mathrm{Bar}=1 \mu \mathrm{m}$.

Figs. 8, 9. Light micrographs of the kidney from E18 (Fig. 8) and E20 (Fig. 9) embryos treated for immunohistochemistry with anti-UTI antibody. The immunoreactivity is localized in part (Fig. 8) and most (Fig. 9) of the regions of proximal tubules. Fig. $8 \times 40 ;$ Fig. $9 \times 100$.

Fig. 10. Electron micrograph of the kidney from E20 embryo treated for immunocytochemistry with anti-UTI antibody. A proximal tubular epithelial cell is shown. Gold particles are accumulated densely in the lysosomes of apical cytoplasm (arrows). $\times 11,000 ; \mathrm{Bar}=1 \mu \mathrm{m}$. 

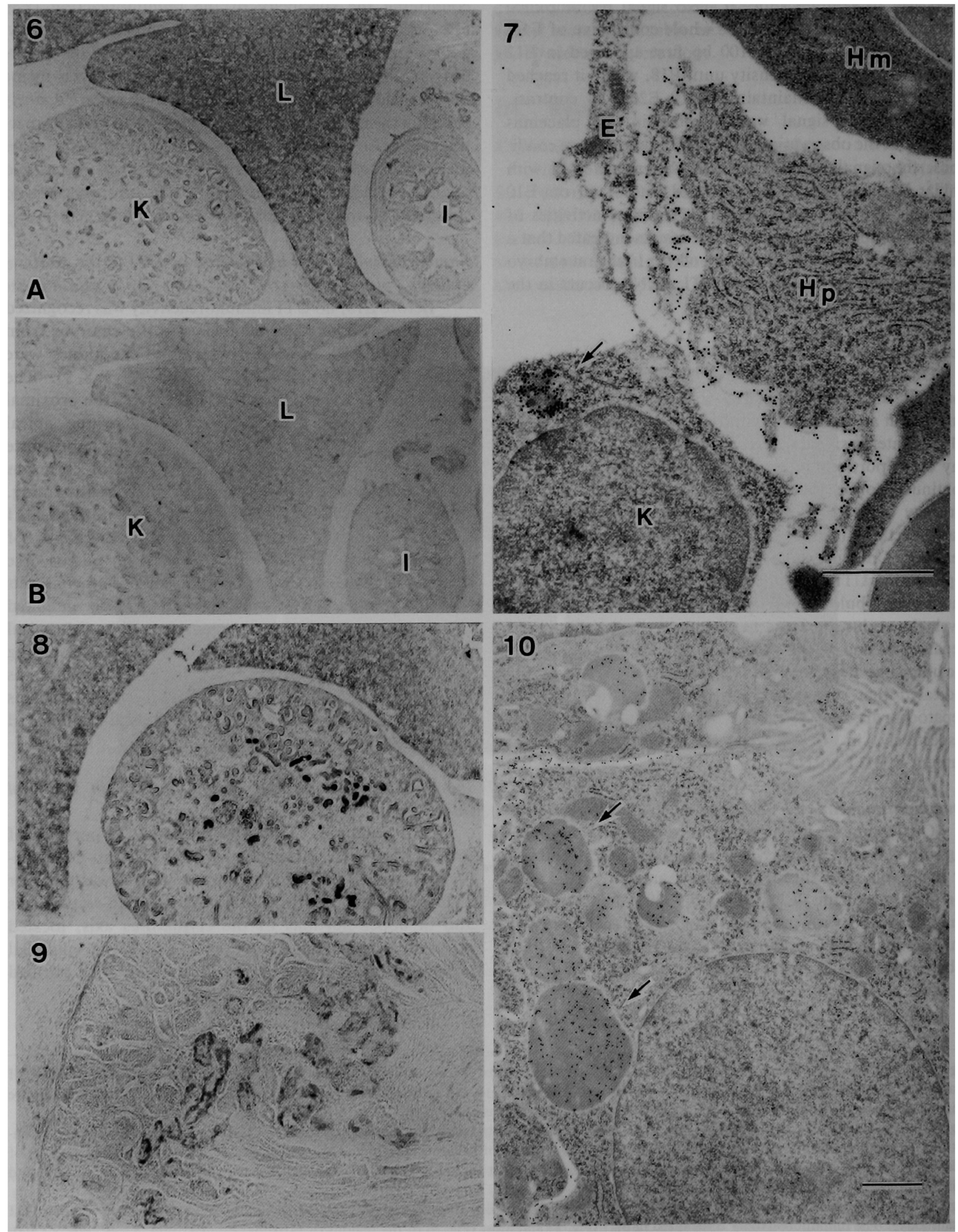

Figs. 6-10 


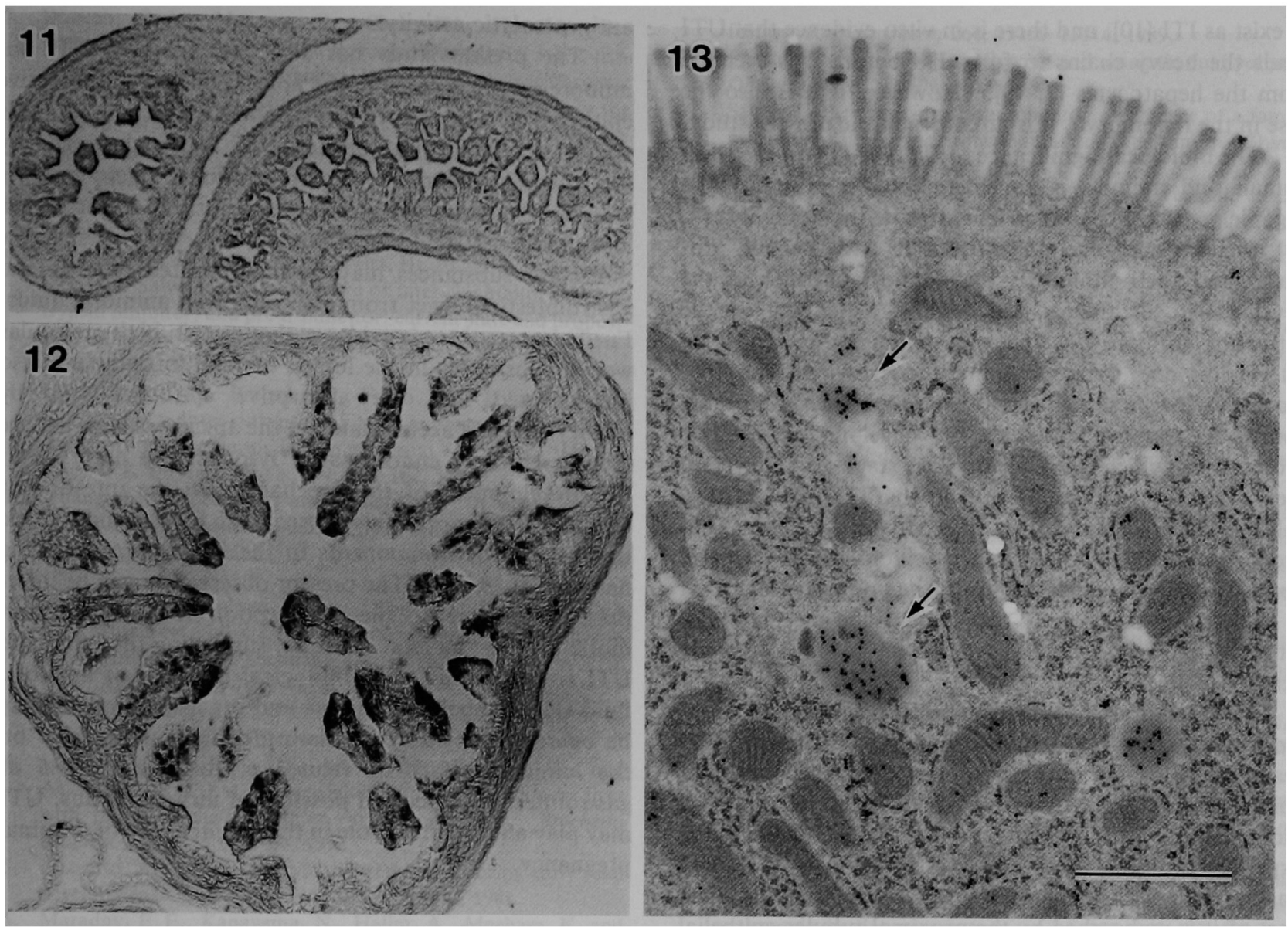

Figs. 11, 12. Light micrographs of the proximal part of intestine from E18 (Fig. 11) and E20 (Fig. 12) embryos treated for immunohistochemistry with anti-UTI antibody. The immunoreactivity is localized in part (Fig. 11) and most (Fig. 12) of the epithelial regions of villi. Fig. $11 \times 40$; Fig. $12 \times 100$.

Fig. 13. Electron micrograph of the proximal part of intestine from E20 treated for immunocytochemistry with anti-UTI antibody. An absorptive epithelial cell is shown. Gold particles are accumulated in the electron-dense vesicles of apical cytoplasm (arrows). $\times 21,000$; $\mathrm{Bar}=1 \mu \mathrm{m}$.

UTI abolished the reaction, confirming the specificity of immunoreaction (not shown). On electron microscopic immunocytochemistry, the apical cytoplasmic vacuoles of absorptive epithelial cells, although smaller in number.and size as compared with those of proximal tubular epithelial cells, demonstrated accumulation of gold particles (Fig. 13). In contrast, the goblet cells had no immunoreactivity in any portions.

\section{Discussion}

The present study has confirmed in the prenatal rat, on the basis of localization of both mRNA and immunoreactivity for UTI, that the hepatocyte is the only origin of UTI, as it was previously established in the adult rat [35]. The liver is known to develop from around E11 out of the foregut epithelium [16] and to produce liverspecific marker proteins such as $\alpha$-fetoprotein, albumin, transferrin, transthyretin and retinol-binding protein from E12 $[1,7,32]$. The present results have revealed that UTI is produced from very early stages of liver development, suggesting an important role of UTI in the latter embryonic periods.

The immuno-electron microscopy of embryonic liver demonstrates that UTI reactivity is located primarily on the surface rather than in the cytoplasm of hepatocytes, an observation similar to that in the adult liver [35]. Since UTI (or its combined form, ITI) is known to have hyaluronan-binding activity $[5,11]$, this result suggests that UTI produced in the hepatocytes is promptly secreted into the space of Disse, where a part of it is adsorbed by the hepatocyte surface. Furthermore, it is demonstrated that Kupffer cells have UTI immunoreactivity in their lysosomes, as previously shown in the adult liver, suggesting that a part of secreted UTI is incorporated into Kupffer cells by endocytosis. The absorption by the hepatocyte surface and incorporation by Kupffer cells of UTI may represent local mechanisms that regulate the amount of UTI entering the blood stream. In the adult human the majority of plasma UTI component is known 
to exist as ITI [10], and there is in vitro evidence that UTI binds the heavy chains to form ITI before it is secreted from the hepatocytes [2, 19]. However, if it is also the case in the rat embryo, it is unknown in the present study.

The biological significance of UTI (or ITI) in the adult human and animals is considered to be primarily the organic protection based on its antiproteolytic activity [17, 20]. In the case of embryo, there is evidence that proteases and their inhibitors play important roles in the development of tissues and organs, as shown in the activation of growth factors, epithelium-mesenchyme interaction and differentiation of nervous system [27]. However, the present study has revealed that UTI occurs concurrently coincident with the development of liver around E12, which is a relatively later stage of rat development. Therefore, it seems unlikely that UTI plays critical roles in the tissue and organ differentiation. Taking into account also that the pancreas-specific digestive enzymes appear from around E16-E18 [33], the primary role of UTI is likely the protection of fetal tissues and organs in the latter periods of development based on its antiproteolytic activity.

In the embryonic kidney, from E18, the immuno-electron microscopy has demonstrated that an intense UTI reactivity is located in the lysosomes of proximal tubular epithelial cells, an observation similar to that in the adult kidney [35]. Taking into account that no UTI mRNA is expressed in the kidney, this result suggests that UTI passes through the glomerulus into the primary urine and a part of it is reabsorbed by the proximal tubular epithelial cells. Past studies also indicate that these cells incorporate various low-molecular-weight proteins from the primary urine into their lysosomes from around E18, consistent with the present observation. It is also possible that the excretion of UTI into the fetal urine itself begins earlier than E18, because the apparatus for glomerular filtration is known to develop from as early as E16 [25]. The rate of reabsorption of UTI by the proximal tubular epithelial cells, together with the glomerular filtration rate for UTI, may regulate the amount of UTI excretion into the fetal urine during the terminal periods of rat development.

Past studies have established that the majority of the amount of amniotic fluid in the terminal periods of pregnancy is derived from the fetal urine [22]. In the humans, UTI is known to appear in the amniotic fluid during the later periods of pregnancy [16]. Although there has been no study that quantitates UTI concentration in the rat amniotic fluid, the present result suggests that at least a part of UTI in the rat amniotic fluid of terminal pregnancy is derived from the fetal urine. Since no detectable level of UTI mRNA is expressed in the placenta, the possibility of UTI production and secretion by the placenta seems to be excluded. However, the extent of possible contribution of maternal UTI to amniotic fluid UTI is unknown. The biological role of amniotic fluid UTI may be the protection of fetus and placenta on the basis of its antiproteolytic activity.

The present study has also demonstrated UTI immunoreactivity located in the apical vesicles of absorptive epithelial cells of proximal small intestine from E18. It is widely accepted that the fetus of terminal pregnancy swallows a large amount of amniotic fluid, which, together with the excretion of fetal urine, constitute a circulation mechanism of amniotic fluid [13, 22, 28]. Many low molecular substances may be incorporated by the fetal gastrointestinal tract from the swallowed amniotic fluids. Furthermore, there is evidence that certain high molecular weight substances in the lumen of fetal intestine are also incorporated into the absorptive epithelial cells by endocytosis and accumulated in the apical vesicles that are considered to be endosomal or lysosomal in nature [13]. The development of this mechanism in the intestine of terminal fetus is probably prerequisite for the endocytotic uptake of milk components in the intestine of suckling newborn $[1,3,13]$. The present observation can be interpreted, therefore, as the reabsorption of swallowed amniotic UTI by the fetal intestine, suggesting that amniotic UTI is circulating. The biological function of amniotic fluid UTI, probably the tissue and organ protection, may be operating not only on the outer surface but also on the luminal surface of fetus, i.e., on the mucosa of gastrointestinal tract and possibly of airway. Thus, UTI may play an important role in the maintenance of terminal pregnancy.

\section{Acknowlegments}

The authors wish to thank Mr. S. Yamazaki for photographic work. This study was supported in part by a research grant from Mochida Pharmaceutical Co., Ltd.

\section{References}

1. Balduyck, M., Laroui, S. and Mizon, J.: A proteoglycan related to the urinary trypsin inhibitor (UTI) links the two heavy chains of inter- $\alpha$-trypsin inhibitor. Biol. Chem. Hoppe-Seyler 370; 329-336, 1989.

2. Bourguignon, J., Sesboue, R., Diarra-Mehrpour, M., Daveau, M. and Martin, J. -P.: Human inter- $\alpha$-trypsin inhibitor. Synthesis and maturation in hepatoma HepG2 cells. Biochem. J. 261; 305-308, 1989.

3. Carone, F. A., Peterson, D. R. and Oparil, S.: Renal tubular transport and catabolism of proteins and peptides. Kidney Int. 16; 271-278, 1979.

4. Chan, P. and Salier, J. -P.: Mouse $\alpha-1$-microglobulin/bikunin precursor: cDNA analysis, gene evolution and physical assignment of the gene next to the orosomucoid locus. Biochem. Biophys. Acta 1174; 195-200, 1993.

5. Chen, L., Mao, S. J. T., McLean, L. R., Powers, R. W. and Larsen, L.: Proteins of the inter- $\alpha$-trypsin inhibitor family stabilize the cumulus extracellular matrix through their direct binding with hyaluronic acid. J. Biol. Chem. 269; 28282-28287, 1995.

6. Chomczynski, P. and Sacchi, N.: Single-step method of RNA isolation by acid guanidinium thiocyanate-phenol-chloroform extraction. Anal. Biochem. 162; 156-159, 1987. 
7. Duncan, S. A., Manova, K., Chen, W., Hoodless, P., Weinstein, D. C., Bachvarova, R. F. and Darnell, Jr. J. E.: Expression of transcription factor HNF-4 in the extraembryonic endoderm, gut, and nephrogenic tissue of the endoderm in the embryo: HNF-4 is a marker for primary endoderm in the implanting glastocyst. Proc. Natl. Acad. Sci. USA 91; 7598-7602, 1994.

8. Faarvang, H. J.: Urinary trypsin inhibitor in man ("Mingin"). Scand. J. Clin. Lab. Invest. 17(Suppl 83); 1-78, 1965.

9. Gebhard, W., Hochstrasser, K., Fritz, H., Enghild, J. J., Pizzo, S. V. and Salvesen, G.: Stracture of inter- $\alpha$-inhibitor (inter- $\alpha$ trypsin inhibitor) and pre- $\alpha$-inhibitor: current state and proposition of a new terminology. Biol. Chem. Hoppe-Seyler 371; 13-22, 1990.

10. Hochstrasser, K., Bretzel, G., Feuth, H., Hilla, W. and Lempart, K.: Inter- $\alpha$-trypsin inhibitor as precursor of the acidstable protease inhibitor in human serum and urine. HoppeSeyler's Z. Physiol. Chem. 357; 153-162, 1976.

11. Huang, L., Yoneda, M. and Kimata, K.: A serum-derived hyaluronan-associated protein (SHAP) is the heavy chain in the inter- $\alpha$-trypsin inhibitor. J. Biol. Chem. 268; 26725-26730, 1993.

12. Kaumeyer, J. F., Polazzi, J. O. and Kotick, M. P.: The mRNA for a proteinase inhibitor related to the HI-30 domain of inter- $\alpha$ trypsin inhibitor also encodes $\alpha$-1-microglobulin (protein HC). Nucl. Acid Res. 14; 7839-7850, 1986.

13. Lev, R. and Orlic, D.: Protein absorption by the intestine of the fetal rat in utero. Science 177; 522-424, 1972.

14. Lindqvist, A., Bratt, T., Altieri, M., Kastern, W. and Akerstrom, B.: Rat $\alpha 1$-microglobulin: co-expression in liver with the light chain of inter- $\alpha$-trypsin inhibitor. Biochem. Biophys. Acta 1130; 63-67, 1992.

15. Luzzatto, A. C.: Hepatocyte differentiation during early fetal development. Cell Tissue Res. 215; 133-142, 1981.

16. Maradny, E. E., Kanayama, N., Halim, A., Maehara, K. and Terao, T.: Urinary trypsin inhibitor has a protective effect on the amnion. Gynecol. Obstet. Invest. 38; 169-172, 1994.

17. Nakahama, H., Nakanishi, T., and Sugita, M.: Cytoprotective effects of ulinastatin against hypoxic injury to LLC-PK1 cells. Nephron 68; 411-412, 1994.

18. Odum, L.: Inter- $\alpha$-trypsin inhibitor with a unique chemical structure. Int. J. Biochem. 22; 925-930, 1990.

19. Odum, L.: Biosynthesis of inter- $\alpha$-trypsin inhibitor and $\alpha 1$ microglobulin in a human hepatoma cell line. Int. J. Biochem. 24; 215-222, 1992.

20. Ohnish, H., Kosuzume, H., Ashida, Y., Kato, K. and Honjo, I.: Effects of urinary trypsin inhibitor on pancreatic enzymes and experimental acute pancreatitis. Digest. Dis. Sci. 29; 26-33, 1984.

21. Potempa, J., Kwon, K., Chawla, R. and Travis, J.: Inter- $\alpha-$ trypsin inhibitor. Inhibition spectrum of native and derived forms. J. Biol. Chem. 264; 15109-15114, 1989.

22. Pritchard, J. A.: Fetal swallowing and amniotic fluid volume. Obstet. Gynec. 28; 606-610, 1966.

23. Salier, J. -P.: Inter- $\alpha$-trypsin inhibitor: emergence of a family within the Kunitz-type protease inhibitor superfamily. Trends Biochem. Sci. 15; 435-439, 1990.

24. Sappino, A. -P., Huarte, J., Belin, D. and Vassalli, J. -D.: Plasminogen activators in tissue remodeling and invasion: mRNA localization in mouse ovaries and implanting embryos. J. Cell Biol. 109; 2471-2479, 1989.

25. Schaeverbeke, J. and Cheignon, M.: Differentiaton of glomerular filter and tubular reabsorption apparatus during foetal development of the rat kidney. J. Embryol. Exp. Morph. 58; 157-175, 1980.

26. Schreitmuller, T., Hochstrasser, K., Reisinger, P. W., Wachter, E. and Gebhard, W.: cDNA cloning of human inter-alphatrypsin inhibitor discloses three different proteins. Biol. Chem. Hoppe-Seyler 368; 963-970, 1987.

27. Seeds, N. W., Verrall, S., Friedman, G., Hayden, S., Gadotti, D., Haffke, S., Christensen, K., Gardner, B., Mcguire, P. and Krystosek, A.: Plasminogen activators and plasminogen activator inhibitors in neural development. Ann. NY. Acad. Sci. 667; 32-40, 1992.

28. Shawdunn, J.: The structure of the absorptive epithelial cells of the developing small intestine of the rat. J. Anat. 101; 57-68, 1967.

29. Southern, E. M.: Detection of specific sequence among DNA fragments separated by gel electrophoresis. J. Mol. Biol. 98: 503-517, 1975.

30. Sumi, H., Takada, Y. and Takada, A.: Studies on human urinary trypsin inhibitor. 1. Its modification on treatment of urine with acid. Thromb. Res. 11; 747-754, 1977.

31. Théry, C. and Stern, C. D.: Role of Kringle domain-containing serine proteases in epithelial-mesenchymal transitions during embryonic development. Acta. Anat. 156; 162-172, 1996.

32. Van den Hoff, M. J. B., Vermeulen, J. L. M., De Boer, P. A. J., Lamers, W. H. and Moorman A. F. M.: Developmental changes in the expression of the liver-enriched transcription factors LF-B1, C/EBP, DBP and LAP/LIP in relation to the expression of albumin, $\alpha$-fetoprotein , carbamoylphosphate synthase and lactase mRNA. Histochem. J. 26; 20-31, 1994.

33. Van Nest G. A., Macdonald, R. J., Raman, R. K. and Rutter, W. J.: Protein synthesized and secreted during rat pancreatic development. J. Cell Biol. 86; 784-794, 1980.

34. Vetr, H. and Gebhard, W.: Structure of the human $\alpha 1$ microglobulin-bikunin gene. Biol. Chem. Hoppe-Seyler 371; $1185-1196,1990$

35. Wakayama, T., Mizushima, S., Hirose, J. and Iseki, S.: Urinary trypsin inhibitor: production in the liver and reabsorption in the kidney of the rat. Acta Histochem. Cytochem. 29, 227-236, 1996. 